https://helda.helsinki.fi

\title{
N-Terminal Brain Natriuretic Peptide First Week After Burn Injury
}

\section{Rakkolainen, Ilmari}

2018

Rakkolainen , I, Elmasry , M , Steinvall , I \& Vuola , J 2018 , ' N-Terminal Brain Natriuretic Peptide First Week After Burn Injury ' , Journal of Burn Care \& Research , vol. 39 , no. 5 , pp. 805-810 . https://doi.org/10.1093/jbcr/irx054

http://hdl.handle.net/10138/311496

https://doi.org/10.1093/jbcr/irx054

acceptedVersion

Downloaded from Helda, University of Helsinki institutional repository.

This is an electronic reprint of the original article.

This reprint may differ from the original in pagination and typographic detail.

Please cite the original version. 


\section{$\mathrm{N}$-terminal brain natriuretic peptide (NT-proBNP) first week after burn injury}

Rakkolainen I, MD (1), Moustafa Elmasry M, MD, PhD (2,3), Steinvall I, PhD (2), Vuola J, MD, $\mathrm{PhD}(1)$

(1) Helsinki Burn Centre, Department of Plastic Surgery,

Helsinki University Hospital and University of Helsinki

Helsinki, Finland

(2) Department of Hand Surgery, Plastic Surgery and Burns, and Department of Clinical and Experimental Medicine, Linköping University, Linköping, Sweden

(3) Plastic Surgery Unit, Surgery Department, Suez Canal University, Ismailia, Egypt 
Abstract

Objective: B-type natriuretic peptide has shown promising results as a biomarker for acute kidney injury in general intensive care patients. It may also indirectly reflect fluid balance of the circulation. Among burn patients, it has been observed to indicate excessive fluid resuscitation and organ dysfunction, although its clinical use to indicate acute kidney injury or guide fluid resuscitation has not been validated. The aim of this study was to evaluate whether the $\mathrm{N}$-terminal pro-brain natriuretic peptide values are related to the amount of fluids given after severe burn injury and whether it can act as a novel biomarker for acute kidney injury in these patients.

Methods: Nineteen consecutive burn patients were included. Plasma N-terminal pro-brain natriuretic peptide was measured daily during 1 week from admission. Other variables such as laboratory values and intravenous infusions were also recorded. The association between acute kidney injury and $\mathrm{N}$-terminal pro-brain natriuretic peptide values was analyzed with a multivariable panel regression model, adjusted for burned total body surface area, age, body mass index, and laboratory values.

Results: N-terminal pro-brain natriuretic peptide values varied between single patients, and even more between the patients who developed acute kidney injury. Older age, lower body mass index, and cumulative infusions were independently associated with higher N-terminal pro-brain natriuretic peptide values, whereas acute kidney injury was not.

Conclutions: N-terminal pro-brain natriuretic peptide values correlated with cumulative infusions given during the first week. The authors could not validate the role of $\mathrm{N}$-terminal pro-brain natriuretic peptide as a biomarker for acute kidney injury in burns.

Keywords: Burn injury, N-terminal pro-brain natriuretic peptide, Fluid resuscitation, Acute kidney injury. 


\section{Introduction}

Burn injury causes fundamental changes in hemodynamics and fluid balance by direct and cytokine-mediated pathways. Increased capillary leakage and vaporization from burned skin results in a decrease of the circulating blood volume, although by appropriate fluid resuscitation this volume can be replaced. Recent evidence suggests that intravenous fluids should be administered at least the amount of Parkland formula to avoid acute kidney injury (AKI) (1). However, excessive fluid resuscitation has previously been associated with volume complications such as pulmonary edema, extremity swelling, wound infections, compartment syndrome or decreased cardiac output $(1-4)$.

Monitoring of fluid administration has been based on clinical parameters, such as urine output, blood pressure, tissue perfusion and more invasive hemodynamic monitoring (5). Another approach may be to measure brain natriuretic peptide (BNP) levels. B-Type Natriuretic Peptide (BNP) is a neuroendocrine agent released from cardiac myocytes after ventricular stretching (6). Pro-BNP is secreted from cardiac myocytes into circulation, then enzymatically dissociated into equal molecular amount of N-terminal proBNP (NT-proBNP) and BNP. These molecules have dissimilar clearance and NT-proBNP has a longer half life in blood, $120 \mathrm{~min}$ vs. $20 \mathrm{~min}$ (BNP) $(7,8)$. BNP has a validated role in evaluation of the fluid accumulation often seen in congestive heart failure $(9,10)$. Elevated concentrations have been observed also in acute respiratory distress syndrome (ARDS), possibly as an effect of right ventricular stretch $(11,12)$.

The role of BNP or NT-proBNP in burn fluid resuscitation is not comprehensively understood and it is not yet in routine use though some data has been published. BNP was elevated in burn patients who developed compartment syndrome or pulmonary edema after excessive fluid resuscitation $(13,14)$, likewise NT-proBNP in burn patients who developed sepsis after injury (5). High BNP three days after burn injury was associated with better outcome and a decreased need for fluid administration after day three (15). A Swedish study found that NT-proBNP concentrations were associated with sequential organ failure assessment (SOFA) scoring and size of the burn injury (16). BNP has shown also promising results as a biomarker for AKI in general intensive care. Patients with AKI had elevated BNP levels at admission, 24 hours and 48 hours after admission (17). However studies in decompensated heart failure patients have shown opposite results in predicting cardio-renal syndrome $(18,19)$. Previous studies have observed, that the elimination of plasma BNP is independent of kidney function whereas plasma NT-proBNP tends to rise with decreased glomerular filtration rate (GFR) (20). 
The aim of this study was to evaluate if the N-terminal pro-brain natriuretic peptide values are related to the amount of fluids given after severe burn injury and if it can act as a novel biomarker for acute kidney injury in these patients.

\section{Materials and methods}

Consecutive patients treated in the Helsinki Burn Centre between March 2013 and September 2014 were enrolled with following criteria: Burn injury involved at least 20 percent of total body surface area (TBSA\%) and 15 percent in patients aged 60 years or older. The data gathered included: Age, sex, body mass index (BMI), burned TBSA\%, burn mechanism, escharotomies, The Abbreviated Burn Severity Index (ABSI) (21), The Sequential Organ Failure Assessment (SOFA) scoring (22), need for renal replacement therapy (RRT), duration of intensive care, and outcome. AKI was determined according to the Acute Kidney Injury Network (AKIN) criteria (23), at least stage I impairment (increase in serum creatinine of $\geq 0.3 \mathrm{mg} / \mathrm{dL}=26.4 \mu \mathrm{mol} / \mathrm{L}$ or increase of 1.5 from base line within $48 \mathrm{~h}$ or urine output less than $0.5 \mathrm{~mL} / \mathrm{kg} \mathrm{x} \mathrm{h}$ for $>6 \mathrm{~h}$ ). Patients were divided into AKI and non-AKI groups to investigate the individual effect of AKI to NT-proBNP values and other variables.

The following parameters were collected during the first $48 \mathrm{~h}$ from admission: Plasma potassium, sodium, glucose, arterial base excess (BE), arterial $\mathrm{pH}$ and mean arterial blood pressure (MAP). Plasma C-reactive protein (CRP) concentration was recorded once a day within one week from admission.

Infusions and urine output were recorded hourly within one week after admission. Plasma NTproBNP was collected every $12 \mathrm{~h}$ within first $48 \mathrm{~h}$ from admission and thereafter daily at 6-8 a.m. within one week from admission.

Plasma NT-proBNP was analyzed by Triage ${ }^{\circledR}$, a point-of-care device (Alere Inc., Waltham, MA, USA). It detects NT-proBNP in the range between 5 and $5000 \mathrm{pg} / \mathrm{ml}$ by an ELISA-based immunoassay. Quality control procedure was performed by manufacturer's orders for each batch of test kits.

The patients received standard burn care, which included resuscitation with Ringer lactate by Parkland formula ( $4 \mathrm{ml} \mathrm{kg}^{-1}$ per TBSA\% burned), no colloids within first 8 hours, urine output target $0.5 \mathrm{ml} \mathrm{kg}^{-1}$ body weight). Early excisions were performed according our standard regime starting 2-3 days after injury. All enrolled patients or their relatives gave informed consent to participate in the study and the study was approved by the Research Ethics Review Board of our institution. 
Statistical analysis

Mann Whitney-U test was applied for continuous variables and chi-square test for dichotomous variables. Friedman ANOVA was used to analyse repeated values and Wilcoxon Matched Pairs Test was used post hoc. Probabilities of less than 0.05 were accepted as significant. A multivariable regression analysis for panel data was used (stepwise forward) to analyze the association between NT-proBNP and AKI, adjusting for general variables (age, sex, and body mass index, BMI), burn related (TBSA\%), and clinical variables (such as intravenous fluids, urine output, and the laboratory variables presented above). We used maximum NT-proBNP value each day during day 1 and 2 and the maximum value from days 3-4 and days 5-7 for the regression model. Data were analyzed with the help of STATA (STATA v12.0, Stata Corp. LP College Station, TX, USA).

\section{Results}

The study included 19 patients (Table 1). All patients arrived to the Burn Centre within 10 hours after injury. Mean age was 53.6 years (SD: 16.8, range 15 - 83), mean TBSA\% was $41.3 \%$ (SD: 17.7, range 20 - 83.5), 18 of the patients had flame injuries and one was burned by hot steam. All patients received resuscitation fluids at least the amount of $90 \%$ of Parkland formula during the first 24 hours.

Nine patients (47.4\%) developed AKI during ICU stay and two of them (22.2\%) required RRT, both survived. Two patients $(10.5 \%)$ died, both within $48 \mathrm{~h}$ after admission. They developed progressive multiple organ failure (MOF), and both were diagnosed with AKI. Data of the measurements and demographics by AKI and non-AKI groups are shown in Tables 1 and 2.

The overall pattern was that the NT-proBNP levels increased over time during the first week after burn ( $p<0.001$, Figure 1). NT-proBNP values varied widely between single patients (Figure 2). There were no significant differences in NT-proBNP values between AKI and non-AKI patients by group level, however a greater variance was observed within AKI group (Figure 3). The relationship with NT-proBNP values and plasma CRP values is presented in Figure 4. CRP level increased over time among all patients. The multivariable regression analysis (Table 2) showed that the adjusted difference was (mean) $72.2 \mathrm{pg} / \mathrm{ml}$ (95\% CI -81.5 to 225.8 ) between the patients in the two groups, and the variable AKI did not contribute significantly to the model. Older age, lower 
body mass index, and cumulative infusions were independently associated with higher NT-proBNP values.

\section{Discussion}

\section{NT-proBNP and AKI}

This prospective study followed plasma NT-proBNP changes in 19 consecutive burn patients within one week after admission. AKI was not found to be an independent factor for the variation in NTproBNP values. Previous studies have shown, that the elimination of plasma BNP is independent of kidney function whereas plasma NT-proBNP tends to rise with decreased glomerular filtration rate (GFR) (20). A study of 34 general ICU patients showed that AKI patients had elevated BNP-levels compared to non-AKI patients at admission, 24 hours and 48 hours after admission (17). Two prospective studies of 87 and 126 patients resulted in opposite conclusions of the ability of NTproBNP to predict worsening of kidney function in patients, who were admitted to hospital for acute decompensated heart failure (cardio-renal syndrome) $(18,19)$. We observed aberrantly high NT-proBNP values (> $800 \mathrm{ng} / \mathrm{ml}$ ) in two patients (both diagnosed with AKI) on days four and five. The one suffered from pre-existing atrial fibrillation and developed late AKI on day 14 and the other needed RRT at early phase after arriving to the burn centre. The results of ours and all these studies are not consistent and further research is needed to establish the dependance of NT-proBNP levels on the various factors affecting its secretions during the early phase after burn injury.

\section{NT-proBNP as a guiding factor for fluid resuscitation.}

NT-proBNP values varied greatly between single patients, however at the group level cumulative infusions in the first week correlated to NT-proBNP values. The association was more obvious within non-AKI group, where overall variation of NT-proBNP values was more moderate, see Figure 3. We didn't see a consistent rise of NT-proBNP values related to the amount of fluids given in acute resuscitation period (first 48h), possibly due to great variation of individual tolerance for volume increase and simultaneous decreasing effect of capillary leakage on circulating cardiac peptides $(15,24)$.

In the present study patients were resuscitated with volumes higher than stated in Parkland formula, likewise in many previously published reports of burn care $(16,25)$. The total amount of fluids per $\mathrm{kg} \times \mathrm{TBSA} \%$ was less in the AKI group, possibly explained by the tendency for fluid retention. Thus, the data in this study support NT-proBNP as a marker for the fluid accumulation during the 
first week after severe burn injury. The strength of this finding is further supported by the lack of correlation to AKI or to the inflammatory response measured as CRP.

\section{NT-proBNP and CRP}

Our study showed no relationship between NT-proBNP and CRP. The increase in CRP during the first 3 days after burn seems to occur earlier than the increase in NT-proBNP, which can explain that we did not found a significant association between these variables. The CRP levels increased over time among all patients, likely by a common response on tissue destruction and systemic inflammation associated with the burn injury (26). Contrary to our findings, a recent study on 52 burn patients showed a significant correlation between plasma CRP and NT-proBNP within the first six days after burn injury (16).

\section{NT-proBNP and sepsis}

In another study high NT-proBNP-values were recorded in 54 burn patients with sepsis. The levels were remarkably higher compared to patients without sepsis. NT-proBNP was also accurate to predict sepsis during hospital stay (5). We observed the highest NT-proBNP value of $903 \mathrm{pg} / \mathrm{ml}$ in this study in a non-septic patient. Only one patient showed sepsis, this occurred 48 hours after the end of the study period. This septic patient showed plasma NT-proBNP levels below $150 \mathrm{pg} / \mathrm{ml}$ during the study period, which is notably lower value than seen earlier by Paratz et al. (5). A Finnish multi-centre study of 254 general ICU-patients with sepsis or septic shock showed that elevated NT-proBNP values predicted mortality during hospital stay (27). In the two non-survivors, who died within 48 hours from admission, NT-proBNP stayed at a low level. Some studies on general ICU patients with sepsis, although with small study groups, have reported an association between SOFA score and NT-proBNP $(28,29)$ but our study showed no such association. Plasma sodium, potassium or glucose had no correlation to NT-proBNP values in this study.

\section{Other factors}

Older age was significantly associated with higher NT-proBNP values, which was expected as reference values of NT-proBNP are higher in elderly than with younger patients when NT-proBNP is used to evaluate acute decompensated heart failure (30). This study also showed that smaller BMI and lower arterial $\mathrm{pH}$ (pH only a tendency) at admission were associated with higher NT-proBNP values. This is in agreement with previous findings, where higher BMI has been individually associated with lower circulating BNP levels in 3389 non-cardiac patients (31). Low pH at admission reflects hypoperfusion, which is likely associated with larger burn injuries and critical 
status of the patients, although we did not find an independent association with burn size and NTproBNP levels like noticed in an earlier Swedish study with 52 burn patients (16).

\section{Strengths \& Limitations}

Strengths of the study includes that it is prospective and done on 19 consecutive patients with frequent samplings. The main limitation of this study is the single centre approach with a limited sample size. Another limitations is that we did not use any objective method to measure the ventricular stretch.

\section{Conclusions}

The results of this study indicated that $\mathrm{N}$-terminal pro-brain natriuretic peptide reflects the amount of cumulative infusions administered during the first week after severe burn injury, but the variation between individuals is too large to guide fluid resuscitation.

Older age and lower body mass index, two factors known to correlate with less fluid tolerance, were also associated with higher N-terminal pro-brain natriuretic peptide values. We could not validate either the role of $\mathrm{N}$-terminal pro-brain natriuretic peptide as an early diagnostic biomarker for AKI in burns.

\section{Conflict of interest statement}

The authors declare no conflict of interest.

\section{References}

1. Mason SA, Nathens AB, Jeschke MG. "Hold the Pendulum: Rates of Acute Kidney Injury Are Increased in Patients Who Receive Resuscitation Volumes Less Than Predicted by the Parkland Equation". Ann Surg. 2016 Jul 18.

2. Klein MB, Hayden D, Elson C, Nathens AB, Gamelli RL, Gibran NS, et al. The association between fluid administration and outcome following major burn: a multicenter study. Ann Surg. 2007 Apr;245(4):622-8.

3. Papp A, Uusaro A, Parviainen I, Hartikainen J, Ruokonen E. Myocardial function and haemodynamics in extensive burn trauma: evaluation by clinical signs, invasive monitoring, echocardiography and cytokine concentrations. A prospective clinical study. Acta 
Anaesthesiol Scand. 2003 Nov;47(10):1257-63.

4. Saffle JIL. The phenomenon of "fluid creep" in acute burn resuscitation. J Burn Care Res. 2007 May;28(3):382-95.

5. Paratz JD, Lipman J, Boots RJ, Muller MJ, Paterson DL. A new marker of sepsis post burn injury?*. Crit Care Med. 2014 Sep;42(9):2029-36.

6. Ruskoaho H. Atrial natriuretic peptide: synthesis, release, and metabolism. Pharmacol Rev. 1992 Dec;44(4):479-602.

7. Martinez-Rumayor A, Richards AM, Burnett JC, Januzzi JL. Biology of the natriuretic peptides. Am J Cardiol. 2008 Feb 4;101(3A):3-8.

8. Kim H-N, Januzzi JL. Natriuretic peptide testing in heart failure. Circulation. American Heart Association, Inc; 2011 May 10;123(18):2015-9.

9. Maisel AS, Krishnaswamy P, Nowak RM, McCord J, Hollander JE, Duc P, et al. Rapid measurement of B-type natriuretic peptide in the emergency diagnosis of heart failure. $\mathrm{N}$ Engl J Med. Massachusetts Medical Society; 2002 Jul 18;347(3):161-7.

10. McCullough PA, Nowak RM, McCord J, Hollander JE, Herrmann HC, Steg PG, et al. B-type natriuretic peptide and clinical judgment in emergency diagnosis of heart failure: analysis from Breathing Not Properly (BNP) Multinational Study. Circulation. 2002 Jul $23 ; 106(4): 416-22$.

11. Maeder M, Ammann P, Rickli H, Diethelm M. Elevation of B-type natriuretic peptide levels in acute respiratory distress syndrome. Swiss Med Wkly. 2003 Sep 26;133(37-38):515-8.

12. Yap LB, Ashrafian H, Mukerjee D, Coghlan JG, Timms PM. The natriuretic peptides and their role in disorders of right heart dysfunction and pulmonary hypertension. Clin Biochem. 2004 Oct;37(10):847-56.

13. Howell E, Sen S, Palmieri T, Godwin Z, Bockhold J, Greenhalgh D, et al. Point-of-Care BType Natriuretic Peptide and Neutrophil Gelatinase-Associated Lipocalin Measurements for Acute Resuscitation: A Pilot Study. J Burn Care Res. 2014 Sep 3;:1.

14. Friese RS, Dineen S, Jennings A, Pruitt J, McBride D, Shafi S, et al. Serum B-type natriuretic peptide: a marker of fluid resuscitation after injury? J Trauma. 2007 Jun;62(6):1346-50-discussion1350-1.

15. de Leeuw K, Nieuwenhuis MK, Niemeijer AS, Eshuis H, Beerthuizen GIJM, Janssen WM. Increased B-type natriuretic peptide and decreased proteinuria might reflect decreased capillary leakage and is associated with a better outcome in patients with severe burns. Crit Care. BioMed Central Ltd; 2011;15(4):R161.

16. Lindahl AE, Stridsberg M, Sjöberg F, Ekselius L, Gerdin B. Natriuretic peptide type B in burn intensive care. J Trauma Acute Care Surg. 2013 Mar;74(3):855-61.

17. de Cal M, Haapio M, Cruz DN, Lentini P, House AA, Bobek I, et al. B-type natriuretic Peptide in the critically ill with acute kidney injury. Int J Nephrol. Hindawi Publishing Corporation; 2011;2011:951629. 
18. Legrand M, De Berardinis B, Gaggin HK, Magrini L, Belcher A, Zancla B, et al. Evidence of uncoupling between renal dysfunction and injury in cardiorenal syndrome: insights from the BIONICS study. PLoS ONE. Public Library of Science; 2014;9(11):e112313.

19. Yamashita T, Seino Y, Ogawa A, Ogata K-I, Fukushima M, Tanaka K, et al. N-terminal pro$\mathrm{BNP}$ is a novel biomarker for integrated cardio-renal burden and early risk stratification in patients admitted for cardiac emergency. J Cardiol. 2010 May;55(3):377-83.

20. Tagore R, Ling LH, Yang H, Daw H-Y, Chan Y-H, Sethi SK. Natriuretic peptides in chronic kidney disease. Clin J Am Soc Nephrol. American Society of Nephrology; 2008 Nov;3(6):1644-51.

21. Tobiasen J, Hiebert JM, Edlich RF. The abbreviated burn severity index. Ann Emerg Med. 1982 May;11(5):260-2.

22. Vincent JL, Moreno R, Takala J, Willatts S, De Mendonça A, Bruining H, et al. The SOFA (Sepsis-related Organ Failure Assessment) score to describe organ dysfunction/failure. On behalf of the Working Group on Sepsis-Related Problems of the European Society of Intensive Care Medicine. 1996. pp. 707-10.

23. Mehta RL, Kellum JA, Shah SV, Molitoris BA, Ronco C, Warnock DG, et al. Acute Kidney Injury Network: report of an initiative to improve outcomes in acute kidney injury. BioMed Central Ltd; 2007. p. R31.

24. de Leeuw K, Niemeijer AS, Eshuis J, Nieuwenhuis MK, Beerthuizen GIJM, Janssen WMT. Effect and mechanism of hydrocortisone on organ function in patients with severe burns. J Crit Care. 2016 Dec;36:200-6.

25. Holm C, Mayr M, Tegeler J, Hörbrand F, Henckel von Donnersmarck G, Mühlbauer W, et al. A clinical randomized study on the effects of invasive monitoring on burn shock resuscitation. Burns. 2004 Dec;30(8):798-807.

26. Gabay C, Kushner I. Acute-phase proteins and other systemic responses to inflammation. N Engl J Med. 1999 Feb 11;340(6):448-54.

27. Varpula M, Pulkki K, Karlsson S, Ruokonen E, Pettilä V, FINNSEPSIS Study Group. Predictive value of N-terminal pro-brain natriuretic peptide in severe sepsis and septic shock. Crit Care Med. 2007 May;35(5):1277-83.

28. Piechota M, Banach M, Irzmański R, Piechota-Urbańska M, Kowalski J, Pawlicki L. NTproBNP levels correlate with organ failure in septic patients: a preliminary report. Postepy Hig Med Dosw (Online). 2006;60:632-6.

29. Guaricci AI, Santoro F, Paoletti Perini A, Ioffredo L, Trivedi C, Pontone G, et al. Correlations between NT-proBNP, outcome and haemodynamics in patients with septic shock. Acta Cardiol. 2015 Oct;70(5):545-52.

30. Maisel A, Mueller C, Adams K, Anker SD, Aspromonte N, Cleland JGF, et al. State of the art: using natriuretic peptide levels in clinical practice. Eur J Heart Fail. 2008 Sep;10(9):82439.

31. Wang TJ, Larson MG, Levy D, Benjamin EJ, Leip EP, Wilson PWF, et al. Impact of obesity 
on plasma natriuretic peptide levels. Circulation. American Heart Association, Inc; 2004 Feb 10;109(5):594-600. 